
(C) 2019 by the Arizona Board of Regents on behalf of the University of Arizona. This is an Open Access article, distributed under the terms of the Creative Commons Attribution licence (http://creativecommons. org/licenses/by/4.0/), which permits unrestricted re-use, distribution, and reproduction in any medium, provided the original work is properly cited.

\title{
MULTIPLE RADIOCARBON DATING OF HUMAN REMAINS: CLARIFYING THE CHRONOLOGY AND SEQUENCES OF BURIALS IN THE LATE NEOLITHIC DOLMEN OF OBERBIPP (SWITZERLAND)
}

\author{
Noah Steuri ${ }^{1}$ (1) - Inga Siebke ${ }^{2}$ - Anja Furtwängler ${ }^{3}$ • Sönke Szidat ${ }^{4,5}$ • \\ Johannes $\mathrm{Krause}^{3} \cdot$ Sandra Lösch $^{2} \bullet$ Albert Hafner $^{1,5 *}$ \\ ${ }^{1}$ Institute of Archaeological Sciences, Prehistoric Archaeology, University of Bern, Switzerland \\ ${ }^{2}$ Institute of Forensic Medicine, Department of Physical Anthropology, University of Bern, Switzerland \\ ${ }^{3}$ Institute for Archaeological Sciences, Archaeo- and Palaeogenetics, University of Tübingen, Germany \\ ${ }^{4}$ Department of Chemistry and Biochemistry, University of Bern, Bern, Switzerland \\ ${ }^{5}$ Oeschger Centre for Climate Change Research (OCCR), University of Bern, Switzerland
}

\begin{abstract}
Undisturbed megalithic burials are extremely rare because in addition to human activities, natural disturbances due to water influence and erosion or faunal activity are likely to occur over time. The dolmen of Oberbipp discovered in 2011 provides a unique opportunity for multidisciplinary research since anthropogenic and natural disturbances are minor. Morphological analysis indicates that approximately 42 individuals were buried in the grave chamber. Using archaeological methods alone, it would not have been possible to determine different occupation periods within the inhumations. Neolithic communities often reused dolmen over centuries. Therefore, radiocarbon $\left({ }^{14} \mathrm{C}\right)$ dating is the only method that can solve the question of temporal resolution. Fragments of the same bone element (right femora) were analyzed by two (in some cases three) different laboratories to date all inhumations individually. The aim of this study was threefold: (1) to determine the total occupation time of the dolmen (2) to evaluate the sequence of the burials, and (3) to compare the results of the same skeletal element from different laboratories. In total, 79 radiocarbon dating results from three different laboratories of the right femora $(n=32)$ were obtained. The total time span of the occupation of the dolmen was between 3350 and 2650 BC. The broad application of radiocarbon dating allowed the determination of two occupation periods within the burial.
\end{abstract}

KEYWORDS: dolmen, Megalithic burials, Neolithic burials, radiocarbon dating, Switzerland.

\section{INTRODUCTION}

In Western Europe, prehistoric megalithic dolmen burial sites of the Neolithic follow the Atlantic facade of the continent. Switzerland is located at the eastern edge of the distribution of the megalithic phenomena. In 2011, a mostly intact dolmen was discovered near Oberbipp, in the Canton of Bern (Ramstein 2014; Siebke et al. 2018; Figure 1). During the excavation in 2012, the structure turned out to be mostly undisturbed, including many prehistoric skeletons. Minor disturbances are related to water intrusion and faunal activities. The discovery of such a collective burial is extremely rare and offers unique research opportunities. Therefore, the project "Multidisciplinary research approach to the Swiss Oberbipp dolmen in the context of the Neolithic revolution in Central Europe" was initiated by the Universities of Bern, Switzerland and Tübingen, Germany in 2015. Next to the archaeological examination of the dolmen, two more subprojects are concerned with the analyses of the human remains found in the grave chamber and focus on the bio-anthropological aspects as well as investigating the genomes of individuals.

A short overview of the results of the archaeological examination aims to provide an understanding of the structure and its archaeological context in order to illustrate the need for multiple radiocarbon dating of the human remains. We support the hypothesis that the dolmen was

\footnotetext{
*Corresponding author. Email: albert.hafner@iaw.unibe.ch.
} 


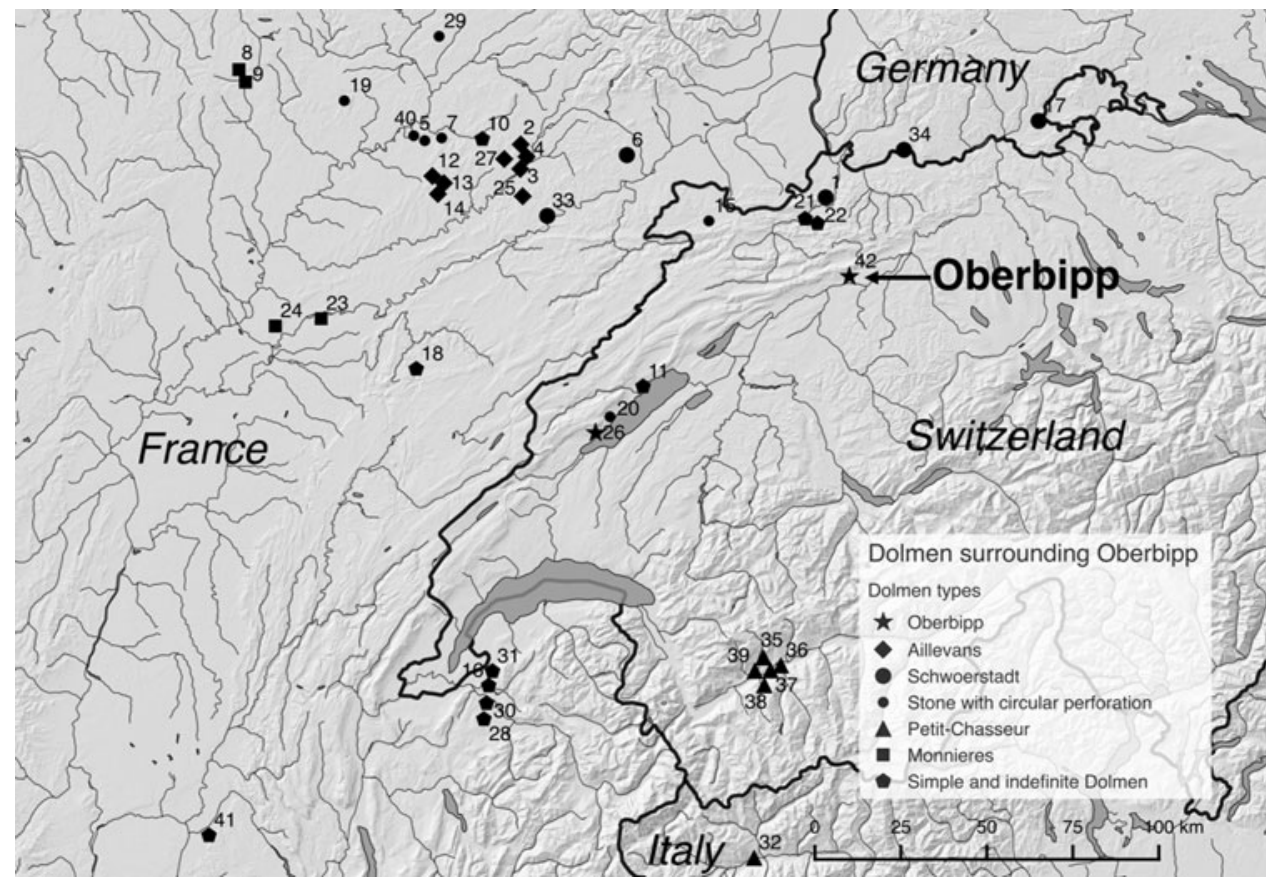

Figure 1 Location of Oberbipp (Canton of Bern, Switzerland) and other megalithic burials in the surrounding area.

built in four significant steps: First, the top layer of earth at the site was removed and the surface leveled. In the following step, two long, parallel trenches were dug and three big stones placed in each, forming the flanks of the dolmen. The third step was the furnishing of the inside of the grave chamber: A threshold was placed in the entrance and rows of flat stones formed the floor of the grave chamber. The last step was the placement of the massive roof stone. Subsequently, the dolmen was used as a burial site. No explicit traces of later human interference (like looting or removing of stones) were detected. However, it was apparent that the structure had been later affected by at least two flooding events, which shifted and displaced some of the stones from the dolmen and affected the uppermost layer of human bones.

At least 42 individuals were buried inside the chamber (Siebke et al. 2019; Figure 2). Due to the combination of flooding events and the replacement of the bones during the use of the dolmen as a burial site, neither individuals nor occupation phases were distinguishable. Most bones were found in one compact burial layer with a preserved profile thickness of 5-20 cm while singular bones were scattered throughout the strata above, which were interpreted as having been replaced due to the flooding events or due to anthropogenic interaction and as having originally belonged to the potentially thicker burial layer. A few artifacts were found inside the chamber, primarily flint arrowheads and animal teeth amulets. Typological dating offers limited insight into the chronology of the dolmen; they are characteristic for the "Horgen" phase of the Neolithic in Switzerland (Stöckli 1995; Hafner and Suter 2012; ca. 3400-2800 BC).

In an area of approximately $200 \mathrm{~km}$ around Oberbipp, at least 41 megalithic collective burials are known. The four dolmen types of "Monnières," "Aillevans," "Schwörstadt" and "Petit-Chasseur" can be distinguished because of their specific architectural features. 


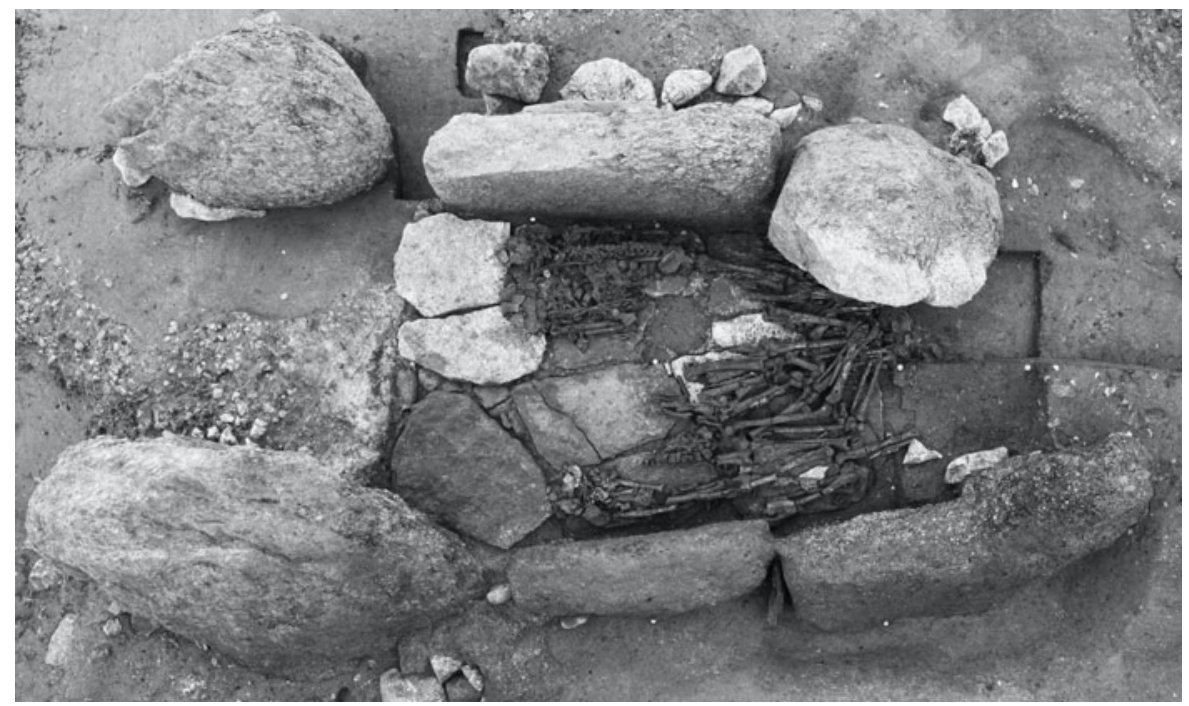

Figure 2 Oberbipp Neolithic dolmen. Top view of the grave chamber after removal of the top stone and most of the burial layer [Photo: Archaeological Service of the Canton of Bern].

The ones that cannot be categorized are addressed as "simple and indefinite dolmen" (Figure 1). With the study of grave goods and architectural changes, it was possible to create the basic chronology for the types. However, dating of dolmen is generally difficult due to their function as diachronic burials and their use over centuries (Stöckli and Moinat 1995). Radiocarbon data are available for $17 \%(n=7)$ of the surrounding megalithic collective burials whereas bones have only been radiocarbon dated at five of the seven sites (the remaining two were dated by charcoal samples). The number of samples per site is small, with individual radiocarbon data between one and six dates for whole sites. The comparison of the architectural features of the dolmen of Oberbipp with the surrounding sites revealed that only the disturbed structure from Onnens in Switzerland (Falquet and Burri-Wyser 2016) with one available radiocarbon dating of a human bone from 2465-2065 cal BC ( $2 \sigma$ range) shows similarities, which justifies the introduction of the new dolmen type of "Oberbipp."

\section{MATERIAL AND METHODS}

The fact that no occupation periods or complete individuals could be differentiated within the burial layers resulted in the need to date all individuals separately. Since we were dealing with commingled human remains, we chose a skeletal element with a sufficient amount of compact bone, suitable for collagen extraction and subsequent radiocarbon dating. Therefore, we decided to conduct the radiocarbon dating on the right femora, which indicated good collagen preservation. The 32 right femora from the grave chamber represent a majority of the buried individuals $(n=42)$. Some right femora fragments could not be evaluated due to their limited preservation.

Three random bone samples from the grave chamber had already been radiocarbon dated during the excavation, dating between 3350 and 2900 BC ( $2 \sigma$ range) (femur: ETH-52562; $4430 \pm 30 \mathrm{BP}$; this sample had an atomic $\mathrm{C} / \mathrm{N}$ ratio of 3.6 and did therefore not meet the 
quality control, tibia: ETH-54434; $4440 \pm 30$ BP, fibula: ETH-52565; $4355 \pm 30$ BP). Precise dating of the individual femora was regarded as essential. We therefore decided to have them analyzed by two different laboratories: Approx. $2 \mathrm{~g}$ from each femur were sampled, divided and analyzed simultaneously at LARA Bern and CEZA Mannheim. Discrepancies or otherwise remarkable results were verified with an additional dating by ORAU Oxford (and in three cases bone samples were dated again at LARA, see "Control Dating and Repetitions" section).

At LARA, bone dating was performed according to Szidat et al. (2017). The surface of the bones was cleaned by mechanical abrasion and ultrasonication in ultra-pure water. After drying, the bones were ground to $0.5-1 \mathrm{~mm}$ using a ball mill (MM 400, Retsch, Haan). An acid-base-acid (ABA) procedure was performed at room temperature: $0.5 \mathrm{~mol} / \mathrm{L}$ hydrochloric acid $(\mathrm{HCl})$ for $60 \mathrm{hr}, 0.25 \mathrm{~mol} / \mathrm{L}$ sodium hydroxide $(\mathrm{NaOH})$ for $1 \mathrm{hr}, 0.5 \mathrm{~mol} / \mathrm{L} \mathrm{HCl}$ for $1 \mathrm{hr}$. For bones of low collagen preservation, the first acid step was shortened to $1 \mathrm{hr}$ as indicated, see section "Control Dating and Repetitions." Afterwards, the material was gelatinized in diluted $\mathrm{HCl}$ at $\mathrm{pH} 3$ and $60^{\circ} \mathrm{C}$ overnight. The warm solution was then filtered using precleaned Ezee-Filters and lyophilized (Alpha 2-4 LSC, Martin Christ Gefriertrocknungsanlagen GmbH, Osterode am Harz) overnight. The extracted collagen was combusted and graphitized with an automated graphitization equipment (AGE). The ${ }^{14} \mathrm{C}$ measurements were performed with the accelerator mass spectrometry (AMS) system MICADAS at the LARA laboratory at the University of Bern, Switzerland, using ${ }^{14} \mathrm{C}$-free sodium acetate and the NIST standard oxalic acid II (SRM 4990C) for blank subtraction, standard normalization, and correction for isotope fractionations (Szidat et al. 2014). The radiocarbon ages were transformed into calendar ages with the OxCal 4.3 software (Bronk Ramsey 2009a) using the IntCal13 calibration curve (Reimer et al. 2013).

Dating at CEZA was performed according to Lindauer et al. (2015) and Kromer et al. (2013). In short: Collagen was extracted from the bone samples and separated the fraction $>30 \mathrm{kD}$ by using ultrafiltration (to remove contamination). The fraction was then lyophilized and combusted to $\mathrm{CO}_{2}$ using an elementary analyzer. The resulting $\mathrm{CO}_{2}$ was catalytically reduced to graphite and ${ }^{14} \mathrm{C}$ measured at the accelerator mass spectrometry (AMS) system at the Klaus-Tschira-Archäometrie-Zentrum at the Curt-Engelhorn-Zentrum Archäometrie gGmbH, University of Heidelberg in Mannheim, Germany. Radiocarbon ages were calibrated using the IntCal13 calibration curve (Reimer et al. 2013).

Dating of the femora samples sent to ORAU was performed according to Brock et al. (2010). The surface was cleaned by air abrasion before being sampled. Samples were afterwards treated with 0.5 $\mathrm{mol} / \mathrm{L} \mathrm{HCl}$ (between 3 to 4 rinses over approx. $18 \mathrm{hr}$ ). The resulting crude collagen was gelatinized in a diluted $(\mathrm{pH} 3) \mathrm{HCl}$ solution at $75^{\circ} \mathrm{C}$ for $20 \mathrm{hr}$ and the resultant gelatin solution was then filtered using a cleaned Ezee-filter. The filtrate was transferred into a pre-cleaned ultrafilter (VivaspinTM 15-30 kD MWCO) and centrifuged until $0.5-1.0 \mathrm{~mL}$ of the $>30 \mathrm{kD}$ gelatin fraction remained. The gelatin was then removed from the ultrafilter with ultrapure water and subsequently freeze-dried at $-18^{\circ} \mathrm{C}$ for a minimum of $12 \mathrm{hr}$. Then samples are measured for their stable isotopic composition of carbon and nitrogen with an elemental analyzer. After being combusted to $\mathrm{N}_{2}$ and $\mathrm{CO}_{2}$, samples were admitted into the mass spectrometer. The remaining $98 \%$ of the $\mathrm{CO}_{2}$ gas was transferred from the splitter and collected cryogenically. Samples were graphitized according to Dee and Bronk Ramsey (2000) and subsequently dated at the ORAU HVEE AMS system as described by Bronk Ramsey et al. (2004). 


\section{RESULTS}

\section{Initial Analysis: Quality Control and Interlaboratory Comparison (LARA and CEZA)}

The initial analysis of the results consisted of the quality control for the radiocarbon data. The criteria are based on Szidat et al. (2017) and van Klinken (1999) and focus on the atomic C/N ratio and the collagen yield $(\% \mathrm{w} / \mathrm{w})$. Samples with an atomic $\mathrm{C} / \mathrm{N}$ ratio of the range between 3.1 and 3.5 are considered as samples with sufficient collagen preservation (see also Brock et al. 2012; Fülöp et al. 2013; Cersoy et al. 2017). The ratio of the dry weights of the lyophilisate and the original bone powder is referred to as lyophilization yield in Table 1. For samples with a carbon content of $<35 \%$, we assume admixtures of inorganic salts residues to the extracted collagen that are supposed not to influence the dating result (van Klinken 1999). In such cases, collagen yields are corrected from lyophilization yields based on the deviation of the carbon content from $35 \%$. The collagen yield should be at least $1 \%$. Samples with yields between 0.5 to $1 \%$ are carefully examined and gelatin yields $<0.5 \%$ are rejected. The samples with sufficient collagen quality were then used for the calibration of the ${ }^{14} \mathrm{C}$ measurements using the IntCal13 curve (Reimer et al. 2013) and the software OxCal 4.3 (Bronk Ramsey 2009a). All radiocarbon data are compiled in Table 1.

Of the femora samples analyzed at CEZA Mannheim $(n=31), 21$ meet the quality control. LARA Bern provided 24 valid radiocarbon data for the femora samples $(n=32)$. Consequently, the results of 17 femora samples could be directly compared with each other. The following interlaboratory comparison is based on the uncalibrated radiocarbon ages $(B P \pm 1 \sigma)$ of these bones $(n=17)$. Of these results, $76 \%(n=13)$ showed consensus between both laboratories dating into the timespan of 3350 to 2950 BC. A bias between both laboratories was not visible and the measurements are uniform: In total, the 13 femora exhibited an average deviation of \pm 30.8 years between the radiocarbon ages. Measurement uncertainties ranged between 20 and 25 years with an average of 21.9 years for CEZA, whereas they were less homogenous for LARA. Here, they ranged between 20 and 45 years (overall average: 29.2 years).

The remaining four data of the double-dated femora, however, showed remarkable discrepancies; either between the two results of the laboratories or they deviated considerably from the established timespan of the other 13 femora. Two samples $(125123,127054)$ showed a difference between the radiocarbon ages of the two laboratories of up to 500 years. The initial results of LARA (Lab codes BE-6204.1.1, BE-6175.1.1) date them much older than the other samples, whereas the corresponding results of the CEZA do not imply a larger age. In that context, also the single result from LARA for 125128 (Lab code BE-6195.1.1) showed a significantly older radiocarbon age as well.

Furthermore, the radiocarbon ages of the two femora $125121-1$ and 125122 are surprising, as both LARA and CEZA date them 250 years younger than the majority of the samples with no overlapping with the other results.

\section{Control Dating and Repetitions}

A subset of the bones $(n=11)$ was sent to ORAU Oxford for control dating (Table 1). The subset mainly involves the two femora dating into a younger period and the three femora with significant discrepancies between the results from CEZA and LARA and/or an indication of a significantly older radiocarbon age. Furthermore, there were four femora with no valid radiocarbon data from LARA or CEZA. The remaining selected samples 
Table 1 Radiocarbon results $(n=79)$ of the femora $(n=32)$. Dates are rounded to the nearest 5 years. Invalid data is marked $(*)$, indicating where it does not meet the quality control criteria. Radiocarbon ages in square brackets refer to those measurements that failed the quality control criteria; they are given for information only and are not used for further interpretation. Interlaboratory comparison was not possible for 126411 due to the little amount of available bone material (neonate). 125121 and $125121-1$ are two different individuals. If several successful analyses were available for one sample, data were combined using the respective function in OxCal. For cases, where this was not applicable due to a negative chi-square test, averages and standard deviations were calculated from the individual measurements in order to consider the whole variability of the data for calibration.

\begin{tabular}{|c|c|c|c|c|c|c|c|c|}
\hline $\begin{array}{l}\text { Femur } \\
\text { sample }\end{array}$ & $\mathrm{Lab}$ & Lab code & $\begin{array}{l}{ }^{14} \mathrm{C} \text { age } \\
(\mathrm{BP} \pm 1 \sigma)\end{array}$ & $\begin{array}{l}\text { Calibrated } \\
\text { age } \\
(\mathrm{BC}, 2 \sigma \\
\text { range })\end{array}$ & $\begin{array}{l}\text { Atomic } \mathrm{C} / \mathrm{N} \\
\text { ratio }\end{array}$ & $\mathrm{C}(\%)$ & $\begin{array}{l}\text { Lyophili- } \\
\text { zation } \\
\text { yield } \\
(\% \mathrm{w} / \mathrm{w})\end{array}$ & $\begin{array}{c}\text { Collagen } \\
\text { yield } \\
(\% \mathrm{w} / \mathrm{w})\end{array}$ \\
\hline 125001 & $\begin{array}{l}\text { LARA Bern } \\
\text { CEZA Mannheim } \\
\text { ETH Zürich } \\
\text { R_Combine } 125001\end{array}$ & $\begin{array}{c}\text { BE-6201.1.1 } \\
\text { MAMS-29648 } \\
\text { ETH-52562 }\end{array}$ & $\begin{array}{c}4510 \pm 45 \\
4465 \pm 25 \\
{[4430 \pm 30]}\end{array}$ & $\begin{array}{l}3360-3035 \\
3335-3025 \\
3335-3030\end{array}$ & $\begin{array}{l}3.3 \\
3.2 \\
3.6^{*}\end{array}$ & $\begin{array}{r}7.5 \\
31.5 \\
14.1\end{array}$ & $\begin{array}{l}8.4 \\
1.3\end{array}$ & $\begin{array}{l}1.8 \\
1.3\end{array}$ \\
\hline 125054 & $\begin{array}{l}\text { LARA Bern } \\
\text { CEZA Mannheim } \\
\text { ORAU Oxford } \\
\text { Average } 125054\end{array}$ & $\begin{array}{l}\text { BE-6182.1.1 } \\
\text { MAMS-29629 } \\
\text { OxA-36308 }\end{array}$ & $\begin{array}{l}4385 \pm 20 \\
4495 \pm 20 \\
4465 \pm 35 \\
4450 \pm 55\end{array}$ & $\begin{array}{l}3085-2920 \\
3340-3095 \\
3340-3025 \\
3340-2930\end{array}$ & $\begin{array}{l}3.2 \\
3.3 \\
3.1\end{array}$ & $\begin{array}{l}33.9 \\
27.2 \\
42.9\end{array}$ & $\begin{array}{l}1.8 \\
5.7 \\
8.1\end{array}$ & $\begin{array}{l}1.7 \\
4.4 \\
8.1\end{array}$ \\
\hline 125074 & $\begin{array}{l}\text { LARA Bern } \\
\text { CEZA Mannheim } \\
\text { R_Combine } 125074\end{array}$ & $\begin{array}{l}\text { BE-6193.1.1 } \\
\text { MAMS-29640 }\end{array}$ & $\begin{array}{l}4465 \pm 20 \\
4460 \pm 25\end{array}$ & $\begin{array}{l}3330-3025 \\
3330-3025 \\
3320-3030\end{array}$ & $\begin{array}{l}3.2 \\
3.4\end{array}$ & $\begin{array}{l}28.9 \\
29.7\end{array}$ & $\begin{array}{l}4.5 \\
3.5\end{array}$ & $\begin{array}{l}3.7 \\
3.0\end{array}$ \\
\hline 125121 & $\begin{array}{l}\text { LARA Bern } \\
\text { CEZA Mannheim } \\
\text { R_Combine } 125121\end{array}$ & $\begin{array}{c}\text { BE-6179.1.1 } \\
\text { MAMS-29626 }\end{array}$ & $\begin{array}{l}4465 \pm 35 \\
4465 \pm 20\end{array}$ & $\begin{array}{l}3340-3020 \\
3335-3025 \\
3325-3030\end{array}$ & $\begin{array}{l}3.2 \\
3.3\end{array}$ & $\begin{array}{l}22.3 \\
26.0\end{array}$ & $\begin{array}{l}1.5 \\
3.4\end{array}$ & $\begin{array}{l}1.0 \\
2.5\end{array}$ \\
\hline $125121-1$ & $\begin{array}{l}\text { LARA Bern } \\
\text { CEZA Mannheim } \\
\text { ORAU Oxford } \\
\text { R_Combine } 125 \text { 121-1 }\end{array}$ & $\begin{array}{l}\text { BE-6191.1.1 } \\
\text { MAMS-29638 } \\
\text { OxA-36309 }\end{array}$ & $\begin{array}{l}4225 \pm 35 \\
4240 \pm 25 \\
4200 \pm 35\end{array}$ & $\begin{array}{l}2910-2680 \\
2910-2760 \\
2900-2670 \\
2895-2760\end{array}$ & $\begin{array}{l}3.2 \\
3.1 \\
3.1\end{array}$ & $\begin{array}{l}13.3 \\
18.6 \\
42.5\end{array}$ & $\begin{array}{l}2.9 \\
1.4 \\
4.9\end{array}$ & $\begin{array}{l}1.1 \\
0.7 \\
4.9\end{array}$ \\
\hline 125122 & $\begin{array}{l}\text { LARA Bern } \\
\text { CEZA Mannheim } \\
\text { ORAU Oxford } \\
\text { Average } 125122\end{array}$ & $\begin{array}{c}\text { BE-6190.1.1 } \\
\text { MAMS-29637 } \\
\text { OxA-36309 }\end{array}$ & $\begin{array}{l}4195 \pm 35 \\
4170 \pm 25 \\
4065 \pm 35 \\
4145 \pm 70\end{array}$ & $\begin{array}{l}2895-2665 \\
2880-2670 \\
2850-2485 \\
2895-2500\end{array}$ & $\begin{array}{l}3.2 \\
3.3 \\
3.1\end{array}$ & $\begin{array}{l}12.7 \\
18.9 \\
43.0\end{array}$ & $\begin{array}{l}2.2 \\
1.5 \\
3.9\end{array}$ & $\begin{array}{l}0.8 \\
0.8 \\
3.9\end{array}$ \\
\hline
\end{tabular}




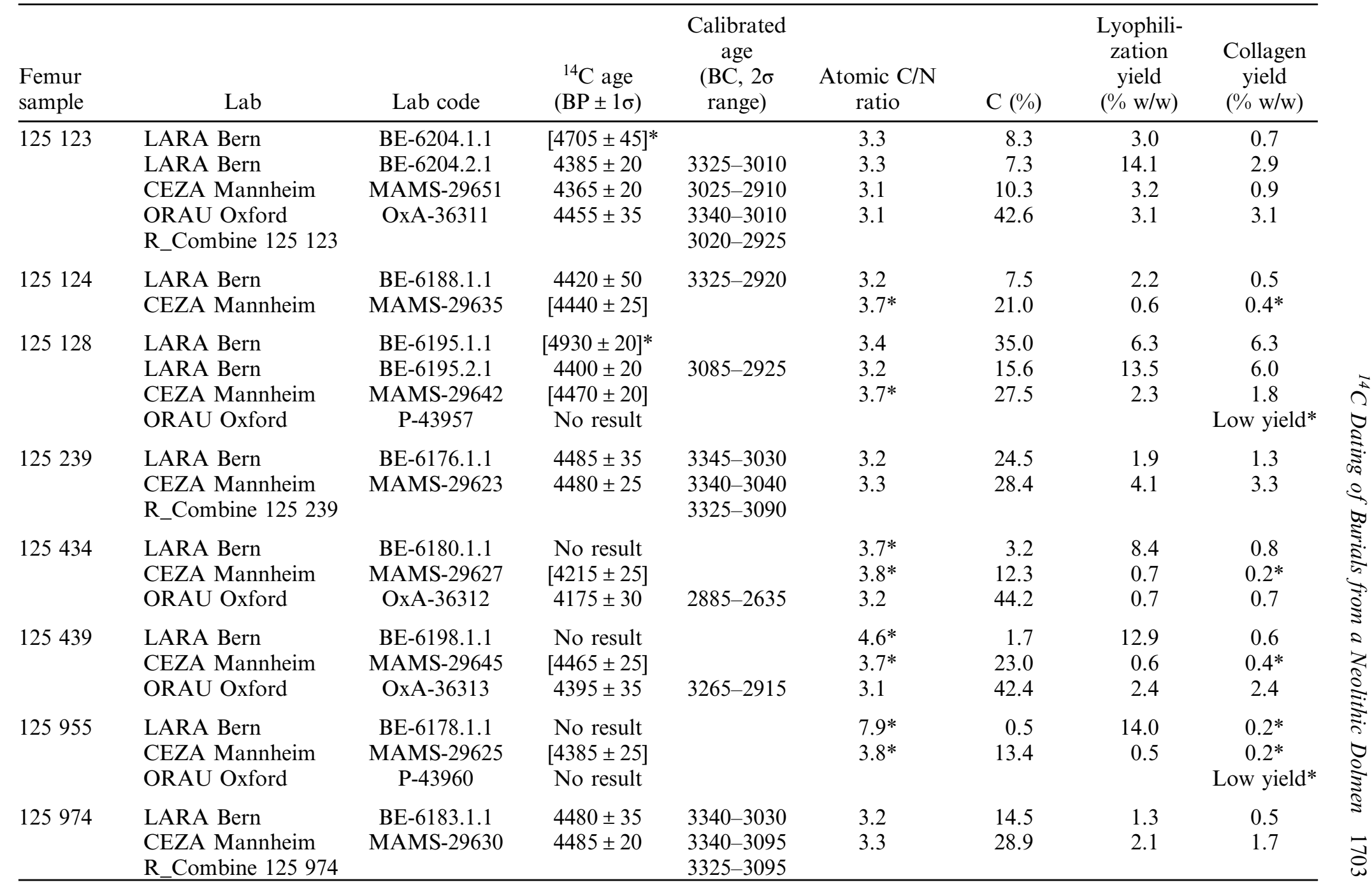




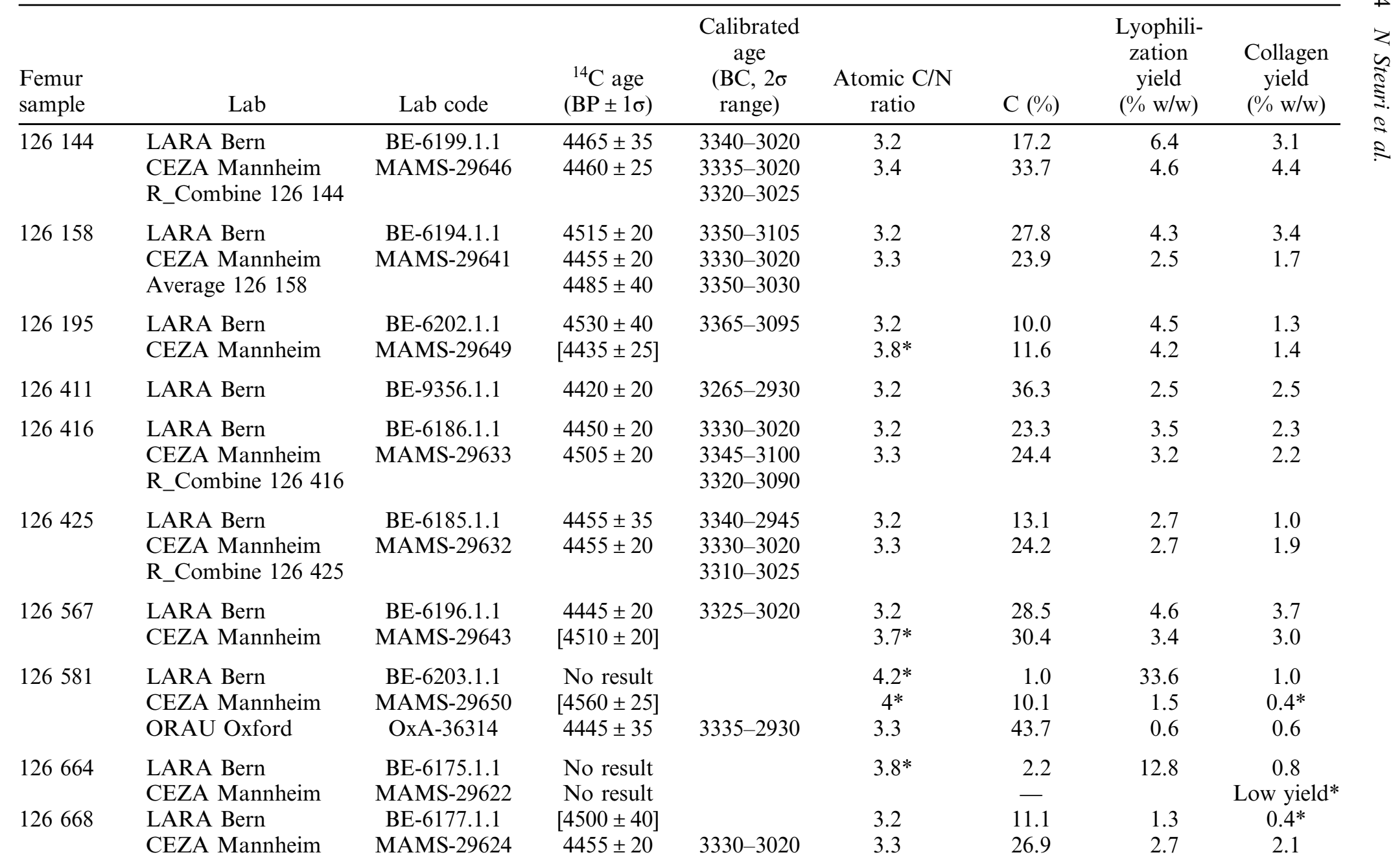




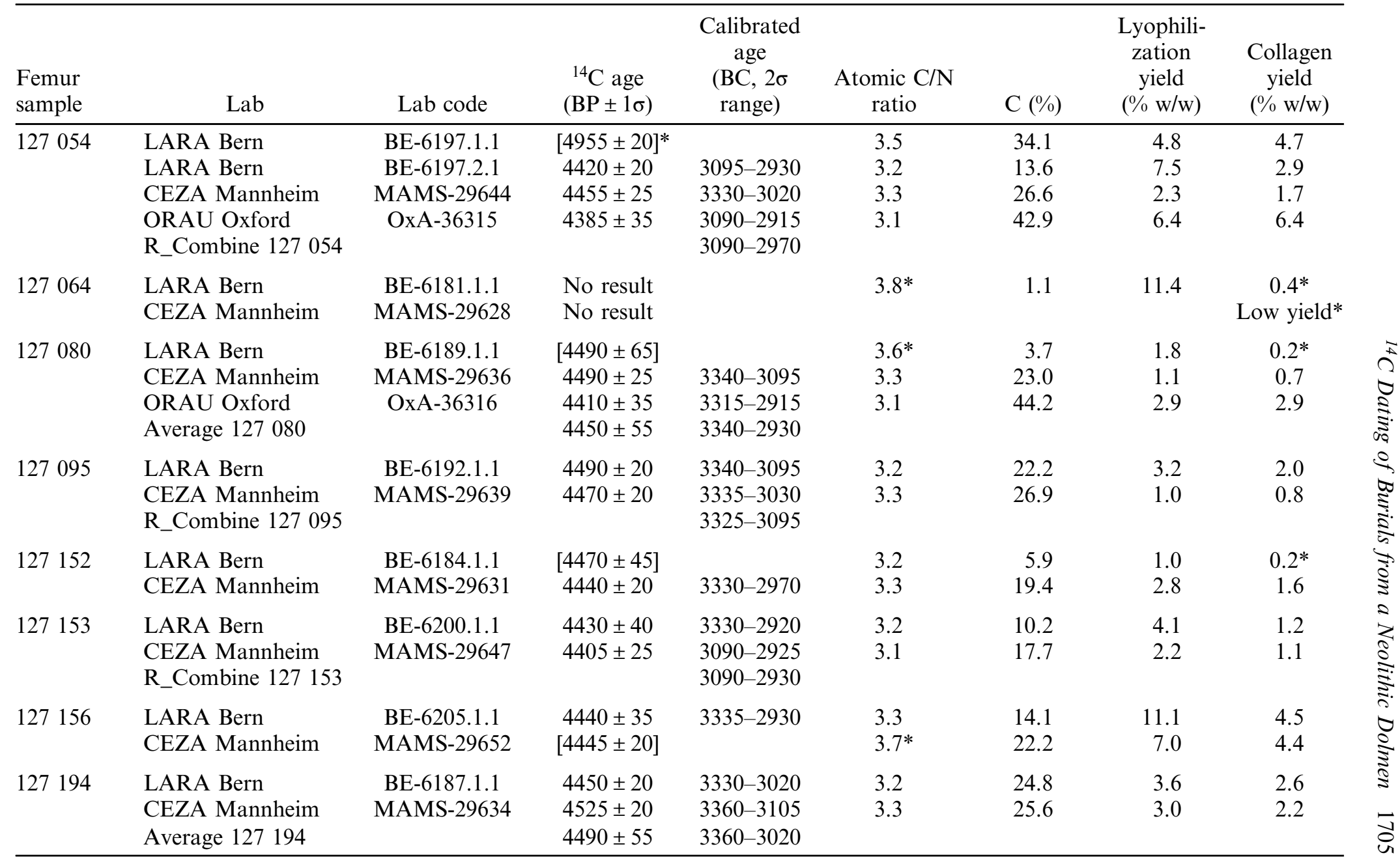


$(n=2)$ do not deviate from the timespan of the majority of the samples and, therefore, do not affect the chronological interpretation of the inhumations.

Of the selected samples $(\mathrm{n}=11)$, ORAU was able to provide results for nine femora (Table 1). These confirmed the assumed younger dating for the two samples (125 121-1, 125122$)$. Additionally, the single valid result from ORAU for 125434 (Lab code OxA-36312) dates this femur also into a younger period. However, the results from ORAU show no evidence for a potential older burial phase as indicated by LARA. In two cases, they are in accordance with the corresponding results from CEZA, placing them to the established timespan of the other femora. The remaining results from ORAU $(n=4)$ likewise date to the same period.

While ORAU performed the control dating, LARA repeated the measurements of the samples that showed a discrepancy with CEZA and/or significantly older radiocarbon ages, namely 125123,125128 and 127 054. As a low yield of collagen extraction had been observed during the first analysis of the samples (Table 1, lab codes: BE-6204.1.1, BE-6195.1.1, and BE-6197.1.1), the sample preparation procedure was modified for the repetition (Table 1, lab codes: BE-6204.2.1, BE-6195.2.1, and BE-6197.2.1). A short first acid step (1 hr) of the ABA procedure was applied instead of the routine protocol (i.e. $60 \mathrm{hr}$ ). All repeated samples were in accordance with the first measurement of CEZA and the results from ORAU. Moreover, two out of the three samples gained a lower $\mathrm{C} / \mathrm{N}$ ratio of the extracted collagen, indicating better preservation of the dated fraction. It should be noted, however, that the $\mathrm{C} / \mathrm{N}$ ratio had already yielded $<3.5$ for all samples when the initial acid step of $60 \mathrm{hr}$ had been applied. This observation reveals that dating biases may occur even if this quality criterion is considered carefully.

\section{DISCUSSION}

\section{Systematic Dating of the Inhumations and Archaeologic Interpretation}

The high amount of radiocarbon samples $(n=79)$ allowed an extensive chronological analysis of the burials. At least one valid measurement is available for $69 \%(n=29)$ of the total individuals (minimum 42). Based on the archaeological examination, the initial assumption of a homogenous burial layer was generally confirmed. Almost $90 \%$ of the femora date into the period between 3350 to $2950 \mathrm{BC}$. More precise dating would be preferable since multiple different burial sequences could have occurred over this span of 400 years. Unfortunately, this period lies directly on a plateau of the calibration curve. This problem could be addressed in the future by genome analysis of the inhumations (regarding the degree of kinship), which are in preparation. The most remarkable result was the discovery of a second occupation period. Based on the independent multiple dating it appears to be certain that three bones are part of a younger phase (Figure 3). No clear association between the radiocarbon dates and the burial position of the femora could be seen, as the burial strata consist of only one compact layer of heavily commingled and fragmented bones. The only evidence that there might have been different burial layers is given by the three younger femora, which derive from the soil directly on top of the burial layer (125 121-1 and 125 122) and from the upper layer of the burial structure (125 434). This femur (125 434) is in close association with two femora (125 074 and 125439$)$ that date to the first burial phase. Whether the femora recovered from the bottom of the burial layer belonged to the first individuals buried in the dolmen cannot be answered by radiocarbon dating yet. 
(a)

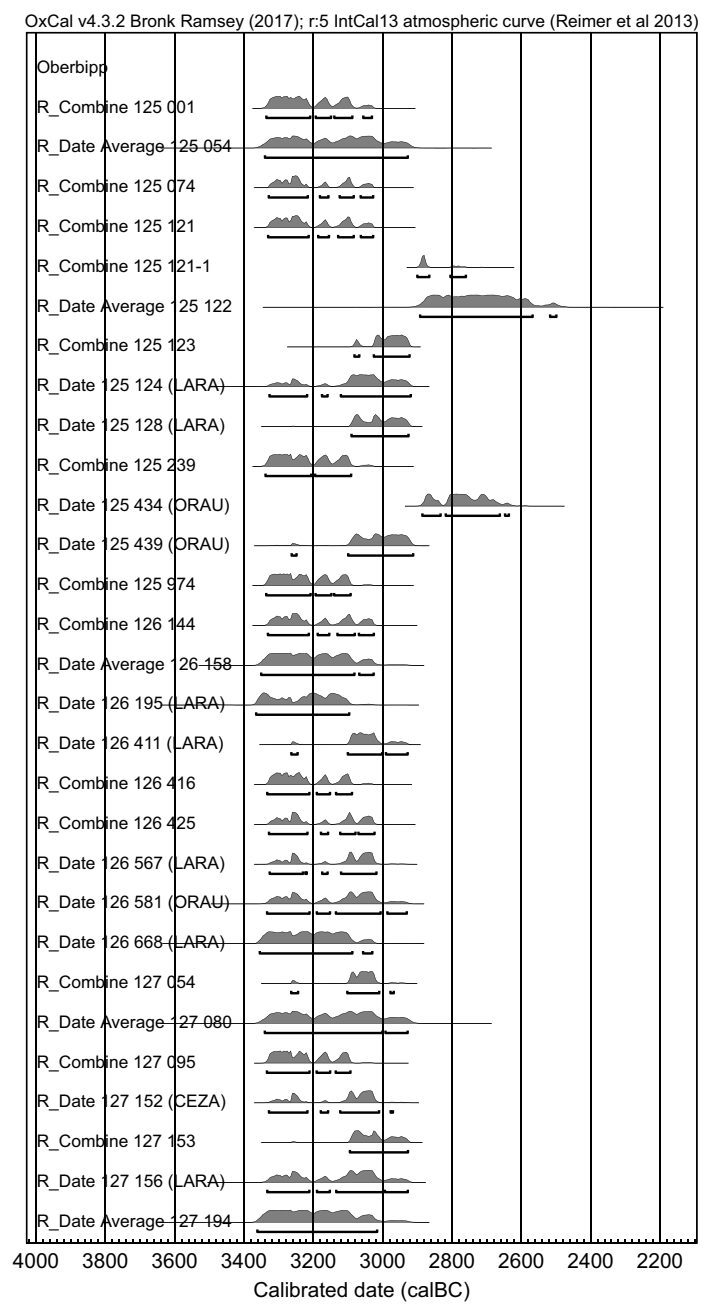

(b) OxCal v4.3.2 Bronk Ramsey (2017); r:5 IntCal13 atmospheric curve (Reimer et al 2013)

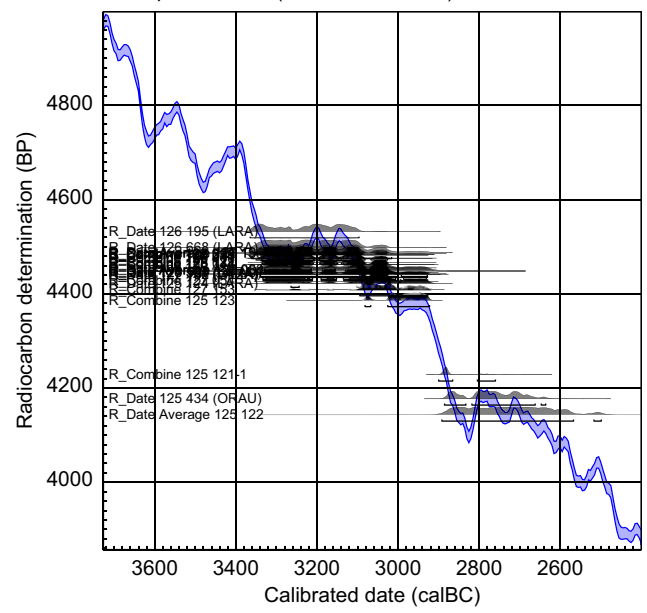

Figure 3 Calendar ages of the valid radiocarbon ages from the femora $(\mathrm{n}=52)$ are displayed as (a) multi-plot and (b) curve plot using the software OxCal v4.3 (Bronk Ramsey 2009a) based on the combined or averaged data from Table 1 where applicable.

One may debate whether single bones are enough to assume the existence of a second burial phase (considering disturbances during the use of the dolmen and in later times). We assume, however, that it is highly unlikely that three femora from the same period entered the burial chamber by accident. A logical conclusion could be that at least three individuals were interred inside the grave chamber as part of a younger burial sequence. It seems that the individuals of the second burial phase were placed on top of the older remains, as indicated especially by femur 125 434. However, further evidence is required to clearly state the burial sequences. The question remains, to what degree this second burial sequence was affected by later natural incidents and how many further remains got washed out of the chamber. 


\section{Methodical Findings of Systematic Radiocarbon Dating}

The large number of radiocarbon dates provide a singular and exceptional opportunity to evaluate the pretreatment methods. There was the need for precise dating of as many individuals as possible, even if they are just represented by femora (the most common skeletal element) to verify our initial research questions. Only thanks to this strategy were the remains of a second burial sequence discovered. Few discrepancies between the results of the laboratories showed the need for control dating by a third laboratory. We therefore recommend radiocarbon dating of all individuals, ideally by multiple laboratories. There could still be remains of additional burial sequences, even if the archaeological analyses do not find any traces of those. It may not be necessary to implement this strategy at every archaeological excavation. However, the discovery of an undisturbed collective burial from the Neolithic was exceptional, and multiple research questions could be approached for the first time.

\section{ACKNOWLEDGMENTS}

We thank the Swiss National Science Foundation (SNSF), project number CR31I3L-157024, and the German Research Foundation (DFG), project number 266057460, for funding the research on the Oberbipp megalithic burial site. Additional thanks go to the Archaeological Service of the Canton of Bern, for providing access to the material from the excavation. We would like to thank John Francuz and Kerstin Fussen, University of Bern, for language editing of the manuscript.

\section{REFERENCES}

Ambrose S. 1993. Isotope analysis of Paleodiets: methodological and interpretive considerations. Food and Nutrition in History and Anthropology 10:59-130.

Brock F, Higham T, Ditchfield P, Bronk Ramsey C. 2010. Current pretreatment methods for AMS radiocarbon dating at the Oxford Radiocarbon Accelerator Unit (ORAU). Radiocarbon 52(1):103-112.

Brock F, Wood R, Higham TFG, Ditchfield P, Bayliss A, Bronk Ramsey C. 2012. Reliability of nitrogen content $(\% \mathrm{~N})$ and carbon:nitrogen atomic ratios $(\mathrm{C}: \mathrm{N})$ as indicators of collagen preservation suitable for radiocarbon dating. Radiocarbon 54(3-4):879-86.

Bronk Ramsey C, Higham T, Leach P. 2004. Towards high-precision AMS: progress and limitations. Radiocarbon 46(1):17-24.

Bronk Ramsey C. 2009a. Bayesian analysis of radiocarbon dates. Radiocarbon 51(1):337-360.

Bronk Ramsey C. 2009b. Dealing with outliers and offsets in radiocarbon dating. Radiocarbon 51(3):1023-1045.

Cersoy S, Zazzo A, Lebon M, Rofes J, Zirah S. 2017. Collagen extraction and stable isotope analysis of small vertebrate bones: a comparative approach. Radiocarbon 59(3):679-694.

Dee M, Bronk Ramsey C. 2000. Refinement of graphite target production at ORAU. Nuclear
Instruments and Methods in Physics Research B 172(1-4):449-453.

Falquet C., Burri-Wyser E. 2016. Le Dolmen d'Onnens, Praz Berthoud. Cahiers d'archéologie romande 159:113-174.

Fülöp R-H, Heinze S, John S, Rethemeyer J. 2013. Ultrafiltration of bone samples is neither the problem nor the solution. Radiocarbon 55 (2-3):491-500.

Hafner A, Suter PJ. 2012. Das Neolithikum in der Schweiz. Journal of Neolithic Archaeology. doi.org/10.12766/jna.2003.4.

Kromer B, Lindauer S, Synal H, Wacker L. 2013. MAMS - A new AMS facility at the CurtEngelhorn-Centre for Achaeometry, Mannheim, Germany. Nuclear Instruments and Methods in Physics Research B 294:11-13.

Lindauer S, Tomasto-Cagigao E, Fehren-Schmitz L. 2015. The skeletons of Lauricocha: new data on old bones. Journal of Archaeological Science: Reports 4:387-394.

Ramstein M. 2014. Ein neolithischer Dolmen an der Steingasse in Oberbipp. Archäologie Schweiz 37:4-15.

Reimer PJ, Bard E, Bayliss A, Beck JW, Blackwell PG, Bronk Ramsey C, Buck C, Cheng H, Edwards RL, Friedrich M, Grootes PM, Guilderson TP, Haflidason H, Hajdas I, Hatté C, Heaton TJ, Hoffmann DL, Hogg AG, 
Hughen KA, Kaiser KF, Kromer B, Manning SW, Niu M, Reimer RW, Richards DA, Scott EM, Southon JR, Staff RA, Turney CSM, van der Plicht J. 2013. IntCal13 and Marine13 radiocarbon age calibration curves $0-50,000$ years cal BP. Radiocarbon 55(4):1869-1887.

Siebke I, Campana L, Ramstein M, Furtwängler A, Hafner A, Lösch S. 2018. The application of different 3D-scan-systems and photogrammetry at an excavation - A Neolithic dolmen from Switzerland. Digital Applications in Archaeology and Cultural Heritage 10. doi.org/10.1016/j.daach. 2018.e00078.

Siebke I, Steuri N, Furtwängler A, Ramstein M, Arenz G, Hafner A, Krause J, and Lösch S. 2019. Who lived on the Swiss Plateau around 3300 BCE? - Analyses of commingled human skeletal remains from the dolmen of Oberbipp. International Journal of Osteoarchaeology. doi.org/10.1002/oa.2791.
Stöckli W 1995. Geschichte des Neolithikums in der Schweiz. Die Schweiz vom Paläolithikum bis zum Mittelalter SPM II:19-52.

Stöckli W, Moinat P. 1995. Glaube und Grabriten. Die Schweiz vom Paläolithikum bis zum Mittelalter SPM II:231-258.

Szidat S, Salazar G, Vogel E, Battaglia M, Wacker L, Synal H-A, Türler A. $2014 .{ }^{14} \mathrm{C}$ analysis and sample preparation at the new Bern Laboratory for the Analysis of Radiocarbon with AMS (LARA). Radiocarbon 56(2):561-566.

Szidat S, Vogel E, Gubler R, Lösch S. 2017: Radiocarbon dating of bones at the LARA Laboratory in Bern, Switzerland. Radiocarbon 59(3):831-842.

van Klinken GJ. 1999. Bone collagen quality indicators for palaeodietary and radiocarbon measurements. Journal of Archaeological Science 26(6):687-695. 